\title{
BONY FISH FAUNAS DIVERSIFICATION IN TRIASSIC PERIOD: OLD AND NEW PROBLEMS
}

\author{
$\underline{\text { Stefano Masini }}$ \\ Earth Sciences Dept. 'A. Desio', Milan University, Via Luigi Mangiagalli 34, Milan, Italy.
}

\section{KEYWORDS: \\ Triassic; \\ fish taxonomy; \\ fish paleontology; \\ subholosteans.}

\section{Bullet-Points Abstract}

- In Triassic period there is a remarkable diversity in actinopterygians bony fishes.

- The application of traditional and modern taxonomic methods returns outcomes difficult to interpret.

- A revision of Triassic actinopterygian groups is desirable to allow the future work of paleontologists.

\section{INTRODUCTION}

Triassic marine ecosystems are among the most fascinating in the Earth History. The PermianTriassic crisis led to an environment extremely depleted of Paleozoic faunas. The few survivors had in that moment the opportunity to diversify and full the empty niches. This phenomenon is well showed also in actinopterygian bony fishes. The Triassic actinopterygian fossil record represents one of the moments with highest diversification (Tintori et al., 2014). In this period, all the major big groups of rayfinned fishes of the Earth history are present (Fig. 1, Carroll, 1988): the chondrosteans (Chondrostei), with the primitive forms of paleopterygians (Paleopterygii) and some groups of derivate forms ("subholosteans"), in addition the first forms of neopterygians with the basal "holosteans" and the probable origin of teleosts (Teleostei).

\section{Discussion}

Traditionally, the terms used above have a significance based on clear characters of jaw and caudal fin anatomy, which adds to the anatomy of other fins, vertebral column structure, and scale coverage. The classic taxonomy of big groups is relatively easy to define following the evolutionary trends of the cited characters. More complicate is to outline the relationships between groups. The modern techniques from genetics and molecular biology can provide the broad relationships between big groups (Hurley et al., 2007). This is possible because we have living representatives also from chondrosteans (Polypteriformes and Acipenseriformes) and "holosteans" (Amia calva and Lepisosteus spp.). More disputable is to force paleontological morphospecies inside a genetic-based phylogeny (Friedman, 2015). For this reason, the traditional approach founded on the morphological interpretation and description is the most reliable method to implement this kind of taxonomy.

Nonetheless, this method is not free of problems. A first issue is the arbitrariness not only of the anatomical interpretation, but also of the choice of the taxonomical categories. By its very nature, biological systematics ought to be approached in the knowledge of its semiotics. Taxonomy should be workable to put in order the groundwork of paleontology. It is risky when it becomes the goal. A clear example about this is given by Triassic orders of Perleidiformes and Peltopleuriformes. The first ones have a remarkable biodiversity, defined as intergeneric diversity. In contrast, Peltopleuriformes show a low biodiversity, but a remarkable variability in small specific characters. In this case, the diversity is defined as intra-generic diversity or phenotypic variability (Masini, 2018). Clearly, paleontologists considered a good solution to make two different orders to divide these subholosteans. Although it is assumed that these systematic groups reflect phylogenetic relationships, their contents manifests difficulties in levelling out the value of taxonomic categories. It means that giving excessive weight to the phylogenetic value of these groups may lead to an incorrect use.

Another big issue in Triassic actinopterygian taxonomy is given by the conservation quality of specimens. For instance, the genus Peltopleurus Kner 1866, the main representative of Peltopleuriformes, has often a bad taphonomic conservation. However, in 


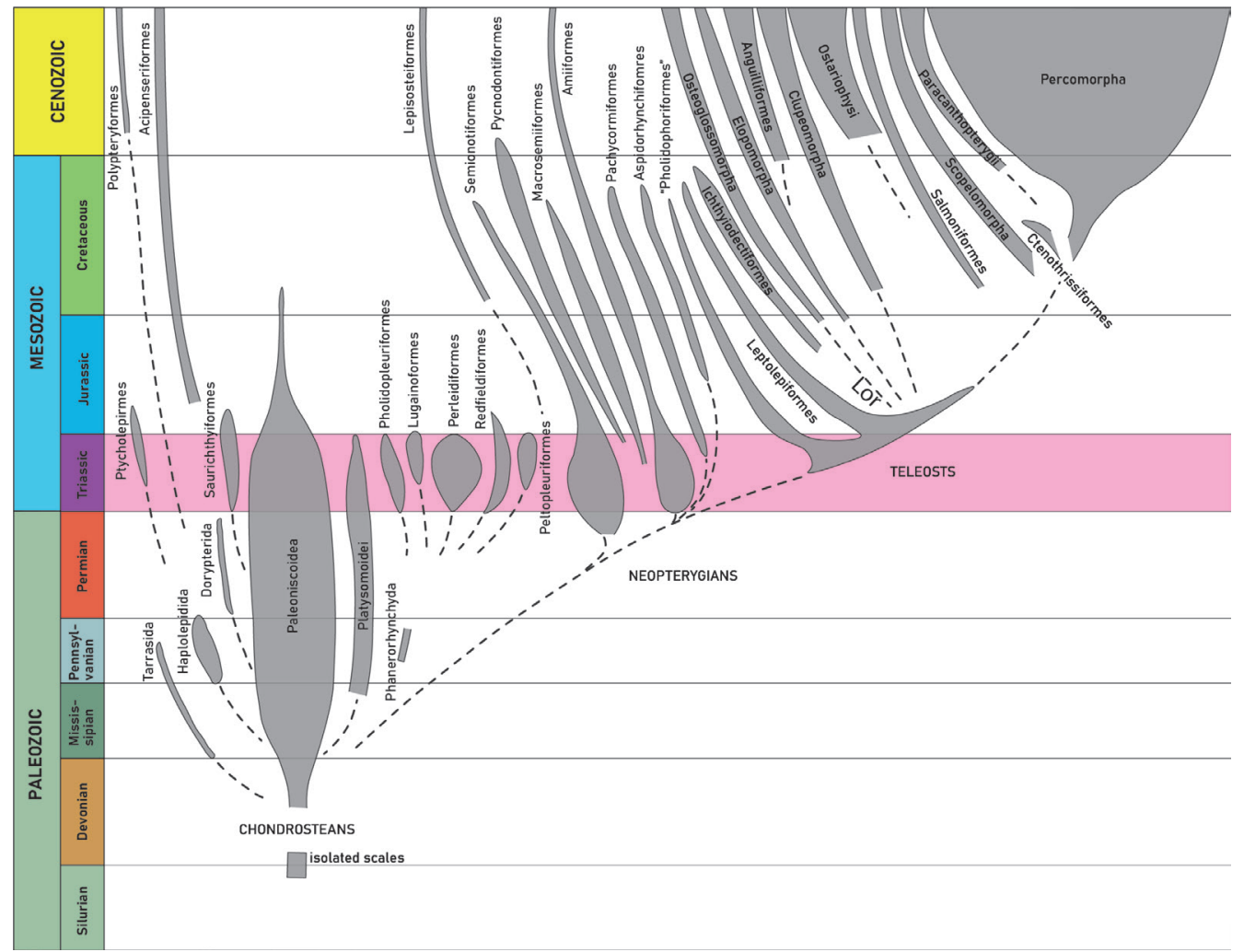

Fig. 1. Overview of the actinopterygian bony fishes phylogeny (modified from Carroll, 1988).

recent literature different specimens of Peltopleurus are inserted in large scale cladograms (Xu \& Ma, 2016; Xu et al., 2018).

With this background, the greatest troubles inside the Triassic radiation are provided by the apparently obsolete group of "subholosteans". With this name paleoichthyologists used to identify a supposed paraphyletic cluster of actinopterygian that appeared in the Lower Triassic: the cited Perleidiformes and Peltopleuriformes along with Pholidopleuriformes, Redfieldiformes, and Lugainoiformes (these last two in need of revision). They have peculiar characters, especially a hemiheterocercal caudal fin with a variable number of epaxial rays, which are inserted dorsally at the terminal part of the notochord. Because of their primitive features, "subholosteans" were clearly included in the chondrosteans. Despite this, in recent literature the "subholosteans" appear as part of early neopterygians (Benton, 2015). This is possible using tiny characters of skull bones (Lopez-Arbarello \& Sferco, 2018). This choice followed recent cladistic systematic practice, in which the investigation of stemand crown-groups is a central issue. This approach is really significant to reconstruct phylogenetic relationships and evolution between present and past, but menaces to overshadow the intricacy of the basal fast radiation.
In addition, the choice of characters and their weight in systematic are problematic. The making of big characters matrices is puzzling because of the phylogenetic relevance of each character and the cited conservation issues. One of the most particular Paleozoic species is Discoserra pectinodon Lund 2000 from Bear Gulch site (Mississippian) in Montana (USA): this deep-bodied fish shows primitive characters of "paleopterygian" chondrosteans, at the same time with a derivate suction feeders-like skull kinesis. Mainly for this reason, it is used in some recent papers as an example of basal neopterygians. This choice is debatable in accordance with $D$. pectinodon datations and other characters. A reasonable explanation for the Discoserra's jaw anatomy could be the evolutionary convergence. Another similar case during Permian and Triassic is the genus Bobasatrania White 1932, a deep-bodied paleopterygian with wide geographical distribution, remarkable variability in size and primitive characters, except for a specific jaws kinesis. Nevertheless, unlike in D. pectinodon, Bobasatrania spp. maintain his place among primitive ray-finned fishes.

\section{ConClusion}

The described cases show how the study of Triassic paleopterygians is complicated by different systematic practices. Despite the importance of this moment in 
Earth's history for the differentiation of modern fish faunas, its study is limited. Unfortunately, an archaic taxonomy with the quality of balance between completeness and clarity is progressively unstructured by new approaches, often limited to small focuses. This generate confusion and difficulty of summary.

Regarding future developments, it is hoped for a broad revision that will consider the whole radiation that occurred in Triassic waters. To do this it is also very important to make a taxonomy workable enough to allow palaeontologists to communicate to each other and to have a clear general view. This probably could be the best way to improve our knowledges on the fascinating bony fish faunas diversification during the Triassic.

\section{REFERENCES}

Benton M.J. (2015). Evolution of Fishes after Devonian. In Benton M.J., Vertebrate Palaeontolgy, Wiley Blackwell: 172-203.

Carroll R.L. (1988). Achantodians and Primitive Bony Fish. In Carroll R.L., Vertebrate Paleontology and Evolution, W. H. Freeman and Company: 84-111.
Friedman M. (2015). The early evolution of ray-finned fishes. Palaeontology, 58(2): 213-228.

Hurley I.A., Mueller R.L., Dunn K.A., Schmidt E.J., Friedman M., Ho R.K., Prince V.E., Yang Z., Thomas M.G. \& Coates M. I. (2007). A new time-scale for rayfinned fish evolution. Proceedings of the Royal Society B: Biological Sciences, 274: 489-498.

López-Arbarello A. \& Sferco E. (2018). Neopterygian phylogeny: the merger assay. Royal Society Open Science, 5(3): 172337.

Masini S. (2018). Nuovi metodi nello studio della variabilità del genere triassico Peltopleurus Kner, 1866 (Osteichthyes, Actinopterygii). Unpublished M.Sc. Thesis, University of Milan: 1-130.

Tintori A., Hitij T., Jiang D., Lombardo C. \& Sun Z. (2014). Triassic actinopterygian fishes: the recovery after the end of Permian crisis. Integrative Zoology, 9(4): 394-411.

Xu G.H. \& Ma X.Y. (2016). A Middle Triassic stemneopterygian fish from China sheds new light on the peltopleuriform phylogeny and internal fertilization. Science bulletin, 61(22): 1766-1774.

Xu G.H., Ma X.Y. \& Zhao L.J. (2018). A large peltopleurid fish (Actinopterygii: Peltopleuriformes) from the Middle Triassic of Yunnan and Guizhou, China. Vertebrata PalAsiatica, 56(2): 106-120. 